the emerging recognition of a new branch of life, the Archaea; it has led to the discovery of submarine and cave-dwelling biotopes that are entirely independent of sunlight; and it has provided insights into the processes of planetary geochemical change. Moreover, extremophiles have potentially important implications for biotechnology and medicine, which are given extensive treatment. Hyperthermophiles are the source of that most valuable biotechnological product, thermostable DNA polymerase, and seem likely to deliver other innovative products and biotechnological processes.

Gross concludes by considering the possibilities for the existence of life in the Universe beyond Earth. The discovery of extremophiles has moved the goalposts in extending the range of conditions and environments considered compatible with life. Nevertheless, the technical problem remains of defining exactly how life, even of a simple microbial form, can be detected by remote probes; the most likely method is the discovery of unexpected gas compositions in planetary atmospheres.

Gross has a writing style that is both informal and entertaining. The text is enlivened by simple line diagrams and a series of vignettes describing a range of topics, including short anecdotal biographies of the principal researchers. The result is a tale of modern biology linking the improved understanding of microbial biodiversity to an impressive range of scientific, medical and commercial advances. It is written at a level that would suit non-specialists, even non-biologists, and therein lies its value: bringing a complex and developing tale of modern biology to a new audience.

Even uncomfortably extreme conditions of temperature, pressure and salinity can be optimal for some species. Perhaps the most challenging problems result not so much from survival under extreme but constant conditions, but from routine exposure to normal but more variable conditions.

Andrew R. Cossins is in the School of Biological

Science, University of Liverpool, Liverpool

L693BX, UK.

e-mail:cossins@liverpool.ac.uk

\section{Designer chemistry}

\section{Eloge du Mixte: Matériaux}

\section{Nouveaux et Philosophie Ancienne}

by Bernadette Bensaude-Vincent

Hachette Littératures: 1998. Pp. 358. FF130

\section{Pierre Laszlo}

From the sledgehammer to the skilled operator and the sophisticated robot, work in a scrapyard requires considerably more discernment than it did 30 years ago. Separating the various materials that make up a car the steel, the aluminium, the platinum, the polyurethane cushions, the vinyl sidings, the elastomers from the tyres, the polyester seat fabrics, the acrylic, the glass windows, the reinforcing glass fibres, and so on - has spawned new companies. Recycling has become a sizeable portion of the plastics industry.

This book addresses the topic of manmade materials, of composites in particular. Its timeliness stems from the advent during the past two decades of a materials science. Seen from physics, it embodied the hope of devising new and interesting problems from the study of 'soft matter', at a distance from traditional solid-state physics. Seen from chemistry, it looked like a new subdiscipline, parallel to molecular science, that would provide common ground for polymer scientists, solid-state chemists, experts in sol-gel processes and suchlike. Important discoveries then helped to boost and buttress materials science.

In 1971, Stephanie Kwolek invented aramides at DuPont de Nemours. The best known among these polyamides is Kevlar, a fibre with, weight for weight, three times the tensile strength of steel. The discovery of carbon nanotubes 20 years later provided materials hundreds of times more resistant than steel that can be turned into electrical wires at the nanometre scale. Yet another unpredicted advance was the discovery in 1986, far from the beaten path, of supraconducting ceramics by Johannes Georg Bednorz and Karl Alex Müller at IBM in Zürich.

The author of this book, Bernadette Bensaude-Vincent, a professor of philosophy and science historian, is well known as a specialist of eighteenth-century French chemistry, and of Antoine Lavoisier in particular. She was recently awarded the Dexter prize in science history by the American Chemical Society.

With this book on materials, she has now moved to an altogether different topic. The first quarter of the book goes back to Greek philosophy: wood is the archetypical material; composites have an ancient history too, going back to Plato's description of crafts in Gorgias, and manifest man's hubris, his daring to contrive artificial fabrics to rival natural products. The second part alludes to the history of the relevant concepts: manmade chemicals such as soda were first made in the eighteenth century; synthetic organic chemicals originated in the nineteenth century. The notion, which we deem modern, of science as the engine for technological innovation can actually be traced back to two Frenchmen, Bernard Palissy - a figure of the Renaissance and a 'Renaissance man' himself — and René Antoine Ferchault de Réaumur, an early theoretician of metallurgy in the eighteenth century.

The third section eulogizes our 'age of plastics', the design of reinforced composite materials and the underlying web of intricate interactions between the component fibres and the associated interwoven surfaces. The final act questions, in the manner of an investigative reporter, the already mythical history of composite materials, seen as fallout from rocket science and other military applications.

Like a lepidopterist, Bensaude-Vincent tends to pin down concepts and then refer to them for 'show-and-tell' stories. But intellectual history is more demanding: there is a desire to understand why the need arose for a given concept, to know how it became embodied in an object, to learn when and why it started to evolve, and to be reminded of its place in our present perception. Bensaude-Vincent is not always reliable in her assertions: alizarine had nothing to do with the synthesis of indigo, and she gets wrong the first name of Jorge Luis Borges.

Her book is easy to read; the style varies from the mundane, as when it smacks of a newspaper article or a report to stockholders, to a racy and supple French prose, as in her description of the art of the synthetic organic chemist, Homo ludens as she names him. But the contents are undermined by their conservatism.

She tries to examine the philosophical issues raised by mankind's new materials. Unfortunately, she does so with a rear-view mirror, showing the traditional fare - Plato for hors-d'oeuvre, Aristotle for the main course and Kant for dessert - instead of a view ahead, through a laminated windshield, at an innovative philosophy to go with the new materials in our life.

Pierre Laszlo is in the Department of Chemistry, Ecole Polytechnique, 91128 Palaiseau, France.

\section{New Journals}

This year, Nature's annual new journals review supplement will appear in the issue of 10 September. Publishers and learned societies are invited to submit journals for review, as well as details of any eligible electronic journals, taking note of the following criteria:

- Journals must have first appeared during or after June 1996 and issued at least four separate numbers by the end of May 1998. - Journals covering any aspect of science are eligible, although those dealing with clinical medicine and pure mathematics are excluded, as are newsletters and publications of abstracts.

- Frequency of publication must be at least three times a year.

- The main language is English.

- Deadline for submission is 5 June.

Please send at least four different issues (the first, the most recent and any two others) of each eligible title, together with full details of subscription rates, to: Peter Tallack, Nature, Porters South, Crinan Street, London N1 9XW, UK. Tel: +44 (0)171 843 4567. e-mail: p.tallack@nature.com 